\title{
Nephroprotective Effect of Pterocarpus indicus Willd. Leaves: Observation From Plasma Urea and Creatinine Levels Against Gentamicin-Induced Nephrotoxicity in Sprague-Dawley Rats
}

\author{
Fadlina Chany Saputri ${ }^{1}$, Fikry Dwi Anjani ${ }^{1}$, Abdul Mun'im ${ }^{2}$ \\ 'Laboratory of Pharmacology, Faculty of Pharmacy, Universitas Indonesia, Depok, 16424, INDONESIA. \\ 2Laboratory of Phytochemistry, Faculty of Pharmacy, Universitas Indonesia, Depok, 16424, INDONESIA.
}

\begin{abstract}
Introduction: Pterocarpus indicus Willd. has been widely used empirically for treating canker sore, antibacterial and kidney disease. Objective: This study aimed to evaluate nephroprotective effect water-boiled P. indicus leaves against gentamicin-induced nephrotoxicity in rats observed from plasma urea and creatinine levels. Materials and Methods: In this study, thirty (30) male rats divided into five treatment groups. The treatment groups consisted of the normal group, induction group received gentamicin $(80 \mathrm{mg} / \mathrm{kg}$ body weight per day i.p.) and a group which received water-boiled $P$. indicus leaves with a dose of $28.8 \mathrm{mg} / \mathrm{kg}, 57.6 \mathrm{mg} / \mathrm{kg}$, and $115.2 \mathrm{mg} / \mathrm{kg}$ body weight per day p.o. All groups received treatment for 21 days. At the $15^{\text {th }}$ day, the animals received gentamicin i.p. for 7 days. At the $22^{\text {nd }}$ day, the blood was collected from orbital sinus. The plasma urea and creatinine levels were measured by Berthelot method for plasma urea and colorimetric method for plasma creatinine. Results: The highest dose of $115.2 \mathrm{mg} / \mathrm{kg}$ water-boiled $P$. indicus was decreased plasma urea
\end{abstract}

and creatinine levels also significantly different $(p<0,05)$ compared induction group. Conclusions: Water-boiled $P$. indicus leaves have a potential to prevent gentamicin-induced nephrotoxicity might be due to its antioxidant and free radical scavenging activity.

Key words: Gentamicin, Nephroprotective, Plasma creatinine, Plasma urea, Pterocarpus indicus Willd.

Correspondence :

Fadlina Chany Saputri

Laboratory of Pharmacology, Faculty of Pharmacy, Universitas Indonesia,

Depok, 16424, INDONESIA.

Phone no: +62217270031

Email: fadlina.chany@farmasi.ui.ac.id

DOI: 10.5530/jyp.2017.1s.11

\section{INTRODUCTION}

Aminoglycoside antibiotics are used to treat infection due to Gram-negative bacteria and bacterial endocarditis. Aminoglycosides are known have toxic effect ototoxic and nephrotoxic. ${ }^{1}$ Approximately $8-26 \%$ of patients who receive aminoglycosides for more than 7-10 days experienced mild renal function impairment. ${ }^{2}$ One of aminoglycoside antibiotics is gentamicin. Toxicity is caused by the accumulation and retention of gentamicin in S1, S2 and S3 segments of the proximal tubular cells that lead to loss brush border integrity. ${ }^{3,4}$ Gentamicin is also known to enhance production of free radicals, tubular necrosis, glomerular congestion, epithelial edema of proximal tubular, cellular desquamation, tubular fibrosis, resulting in reduced glomerular filtration rate and renal function impairment. ${ }^{3,5}$ Kidney damage caused by gentamicin show the same conditions with renal function impairment is clinically characterized by elevated Blood Urea Nitrogen (BUN) and creatinine plasma levels, albuminuria, reduced glomerular filtration rate (GFR), renal dysfunction. ${ }^{3,6}$ Pterocarpus indicus Willd. (Fabaceae) is known as "Angsana" in Indonesia. The majority of Indonesian people have been using leaves for treating various diseases including boils, ulcers, prickly heat rashes. ${ }^{7}$ The community partially in Indonesia consumed leaves with a traditional way young leaves boiled with water for treating kidney dysfunction. The study to prove an efficacy of $P$. indicus is still slightly. The previous research has found that $P$. indicus leaves contain epicatechin that can lower blood glucose levels. ${ }^{8}{ }^{89}$ Another study said that epicatechin can reduce oxidative stress on kidney dysfunction caused by damage to tubular epithelial cells. ${ }^{10}$ It allows the $P$. indicus leaves have a nephroprotective effect but until now there has been no research examining that. This study aimed to prove nephroprotective effect water-boiled $P$. indicus leaves observed from plasma urea and creatinine levels against gentamicininduced nephrotoxicity in Sprague-Dawley rats.

\section{MATERIALS AND METHODS}

\section{Plant Materials}

Fresh leaves of Pterocarpus Indicus Willd. were collected from West Java, Indonesia. The species was identified and authenticated by the Indonesian Institute of Sciences, Bogor, Indonesia, voucher specimen number 13-407/IPH.3./KS/II/2016.

\section{Preparation of Water-Boiled}

Fresh leaves of Pterocarpus indicus Willd be pondered the equivalent of 2.9 grams, then boiled with $500 \mathrm{ml}$ distilled water at $100^{\circ} \mathrm{C}$ for $30-45$ minutes until the volume obtained half of the initial volume to get waterboiled $P$. indicus leaves (WPIL). The concentration water-boiled P.indicus $11.52 \mathrm{mg} / \mathrm{ml}$ per body weight. The amount of the volume is adjusted to body weight of rats. Water-boiled P.indicus leaves is made every day.

\section{Chemicals}

Heparin sodium was purchased from PT. Pharos, Indonesia. Gentamicin injection was purchased from PT. Indofarma, Indonesia. Standard kits used Urea Liquicolor and Creatinine Liquicolor were purchased from Gesellschaft fur Biochemica und Diagnostica mbH, Germany.

Preliminary Phytochemical Analysis 
A preliminary phytochemical analysis of water-boiled P.indicus was done to identification presence various groups of phytochemicals. ${ }^{11}$

\section{Experimental Design}

Male Sprague-Dawley rats (150-200 grams) were kept at standard condition temperature $\left(25 \pm 20^{\unrhd} \mathrm{C}\right)$ and light (12 hours light/dark cycles). They received pellet and water ad libitum. The animals were acclimatized for 1-2 weeks before the experiment. The protocol experiment was approved by Ethics Committee of the Faculty of Medicine, University of Indonesia (Approval No. 236/UN2.F1/ETIK/2016).

Thirty (30) rats were randomly divided into five groups. Group I : Normal group, received aqua pro injection i.p., Group II : Induction group, received gentamicin (GM) (80 mg/kg BW, i.p. for 7 days), Group III : received water-boiled P.indicus leaves (WPIL) $(28.8 \mathrm{mg} / \mathrm{kg} \mathrm{BW}$, p.o.) and GM ( $80 \mathrm{mg} / \mathrm{kg} \mathrm{BW,} \mathrm{i.p.} \mathrm{for} 7$ days), Group IV : received WPIL with (57.6 mg/kg BW, p.o) and GM (80 mg/kg BW, i.p. for 7 days), Group V : received WPIL (115.2mg/kg BW) and GM ( $80 \mathrm{mg} / \mathrm{kg} \mathrm{BW,} \mathrm{i.p.} \mathrm{for} 7$ days). Administration WPIL was started 14 days before administration of gentamicin and it was continued until 21 days. The rats fasted overnight. At the $22^{\text {nd }}$ day, The blood was collected from orbital sinus for measuring urea and creatinine in plasma. Plasma was separated from blood and stored at $-20^{\circ} \mathrm{C}$ until used for biochemical analysis. At the end treatment animals were sacrificed under ether vapor.

\section{Determination of Plasma Urea}

The urea was measured by modified Berthelot's reaction using Urea Enzymatic colorimetric Kit. Urea was hydrolysed in the presence of water and urease produces ammonia and carbon dioxide. Ammonium ions reacted with hypochlorite and salicylate to form a green dye. The absorbance measured at $578 \mathrm{~nm} .^{12}$

\section{Determination of Plasma Creatinine}

The creatinine was measured by Jaffe's method using Creatinine Colorimetric Kit. Creatinine in alkaline solution with picric acid produces an orange-red colored complex. The absorbance measured at $496 \mathrm{~nm} .{ }^{13}$

\section{Statistical Analysis}

All values were represented as Mean \pm standard error means (SEM). Data were analyzed statistically using Kruskal-Wallis test and for the analyzed significant difference between group treatment using MannWhitney test. All probability level of less than $5 \%(\mathrm{p}<0,05)$ was considered statistically significant. The statistical analysis was made by SPSS.

\section{RESULTS}

Phytochemical screening analysis WPIL contained flavonoid and tannins. As summarized in Table 1. Gentamicin-induced nephrotoxicity is characterized by elevated plasma urea and creatinine levels. Induction group showed increased plasma urea and creatinine levels significantly different $(\mathrm{p}<0.05)$ compared normal group. WPIL have a potential to prevent gentamicin-induced nephrotoxicity. This was shown with the administration of WPIL (28.8-115.2 mg/kg) showed decreased plasma urea and creatinine levels with a dependent dose manner. The highest dose of $115.2 \mathrm{mg} / \mathrm{kg}$ WPIL showed significantly different $(\mathrm{p}<0.05)$ compared induction group.

\section{DISCUSSION}

Gentamicin is an aminoglycoside antibiotic that has the most powerful nephrotoxic effects than other aminoglycosides, so it can be accelerated acute renal failure in human and animals subjects. ${ }^{14}$ Kidney damage due to the administration of gentamicin in high doses is functionally characterized by elevated levels of urea and creatinine in plasma. Elevated plasma creatinine indicated occur decreased glomerular filtrate rate. ${ }^{5,15}$ Based on our previous study that gentamicin with a dose of $80 \mathrm{mg} / \mathrm{kg} \mathrm{BW} /$ day i.p. for 7 days has been able to cause kidney damage is characterized by elevated plasma urea and creatinine levels. The toxic effect of gentamicin is closely related to the lysosomal phospholipidosis through inhibition of lysosomal hydrolases. ${ }^{2}$ Gentamicin-induced nephrotoxicity due to accumulation drugs in proximal cells, resulting in loss of brush border integrity, necrosis cells, apoptosis cells, and massive proteolysis. ${ }^{3,16}$ Another mechanism, Gentamicin could be increased generation of reactive oxygen species (ROS) such as superoxide anion $\left(\mathrm{O}_{2}^{-}\right)$, hydroxyl radical $\left(\mathrm{OH}^{-}\right)$, hydrogen peroxide $\left(\mathrm{H}_{2} \mathrm{O}_{2}\right)$, and peroxynitrite anion $\left(\mathrm{ONOO}^{-}\right)$in the renal cortex which damages the structure and function of the kidney. The presence of free radicals could be increased lipid peroxidation characterized by increased malondialdehyde, decreased glutathione (GSH) and antioxidant enzymes. ${ }^{3,17}$

Administration WPIL in rats which gentamicin-induced nephrotoxicity show decreased plasma urea and creatinine levels in a dose-dependent manner. Decreased plasma urea and creatinine levels in Group III and Group IV were not significant $(\mathrm{p}>0.05)$ compared induction group. This probably could be due to the duration of administration WPIL too short. The plasma urea and creatinine levels in Group V were significant ( $\mathrm{p}$ $<0.05)$ compared induction group.

Several phytoconstituents in plant extract demonstrated antioxidant and cytoprotective function. ${ }^{4}$ Flavonoid such as catechin and epicatechin are known to have antioxidant effects, antimicrobial and bactericidal activity. ${ }^{18}$ Decreased plasma urea and creatinine levels due to presence flavonoids and tannins contained in WPIL might be an important role as antioxidant functions. ${ }^{19}$

The previous study has found that WPIL contained epicatechin. Epicatechin has the ability to protect mitochondria from oxidative stress in renal tubules caused by cisplatin with increasing enzyme manganese superoxide and glutathione also inhibit enzyme nicotinamide adenine dinucleotide phosphate (NADPH) oxidase activity. Additionally, epicatechin can inhibit cytochrome $\mathrm{c}$ release and inhibit Bax activation that plays a role in renal tubular cells apoptosis. ${ }^{10}$

Plasma urea level in Group V was still high if it was compared normal range plasma urea in the rat. The normal range of BUN was $10-21 \mathrm{mg} / \mathrm{dl}$ or plasma urea level from 21.4 to $44.94 \mathrm{mg} / \mathrm{dl}$ in the rat. ${ }^{20}$ This probably due to gentamicin besides to attack tubules also cause to mesangial cells contraction, resulting in reduced the coefficient of ultrafiltration and at the end reduced glomerular filtration rate. Plasma urea is not filtered retained in the blood, causing plasma urea level was still high.

Table 1: Effect of water boiled P. Indicus on plasma urea and creatinine levels

\begin{tabular}{cccccc}
\hline Parameters & Normal & GM & $\begin{array}{c}\text { GM+WPIL } \\
(\mathbf{2 8 . 8 ~ m g / k g})\end{array}$ & $\begin{array}{c}\text { GM +WPIL } \\
(\mathbf{5 7 . 6} \mathbf{~ m g} / \mathbf{k g})\end{array}$ & $\begin{array}{c}\text { GM+WPIL } \\
(\mathbf{1 1 5 . 2} \mathbf{~ m g} / \mathbf{k g})\end{array}$ \\
\hline Plasma Urea (mg/dl) & $42.76 \pm 4.90$ & $153.81 \pm 14,79^{\mathrm{a}}$ & $141.12 \pm 10,43^{\mathrm{b}}$ & $116.68 \pm 16.98^{\mathrm{b}}$ & $93.98 \pm 13.24^{\mathrm{c}}$ \\
Plasma Creatinine (mg/dl) & $0.51 \pm 0.08$ & $1.85 \pm 0,31^{\mathrm{a}}$ & $1.34 \pm 0,27^{\mathrm{b}}$ & $1.13 \pm 0.26^{\mathrm{b}}$ & $0.84 \pm 0.10^{\mathrm{c}}$ \\
\hline
\end{tabular}

Note: All values were represented as Mean $\pm \operatorname{SEM}(n=6)$; (a) $P<0.05$ compared normal group; (b) $p>0.5$ compared induction group; (c) $\mathrm{p}<0.05$ compared induction group 


\section{CONCLUSION}

Based on the above results, water-boiled $P$. indicus leaves were used by the public proven to treat kidney disease observed from plasma urea and creatinine levels were decreased after administration water-boiled $P$. indicus leaves. The exact mechanism of Pterocarpus indicus leaves to protect kidney has not been determined in the study.

\section{ACKNOWLEDGEMENT}

This research is supported by Faculty of Pharmacy, Universitas Indonesia and funded by Hibah PITTA Universitas Indonesia.

\section{CONFLICT OF INTEREST}

There is no conflict of interest in this study.

\section{REFERENCES}

1. Lopez-Novoa JM, Quiros Y, Vicente L, Morales Al, Lopez-Hernandez FJ. New insights into the mechanism of aminoglycoside nephrotoxicity: an integrative point of view. Kidney Int. 2011;79(1):33-45.

2. Bushan SH, Ranjan SS, Subhangankar N, Rakesh S, Amrita B. Nephroprotective activity of ethanolic extract of Elephantophus scaber leaves on albino rats. Int Res J Pharm. 2012;3(5):246-50.

3. Balakumar P, Rohilla A, Thangathirupathi A. Gentamicin-induced nephrotoxicity : Do we have a promising therapeutic approach to blunt it. Pharmacol Res. 2010;62:179-86

4. Solomon JA, Ganeshpurkar A, Pandey V, Bansal D, Dubey N. Protective effect of Trichosanthes dioica extract against gentamicin induced nephrotoxicity in rats. Pharmacogn Commn. 2016;6(1):23-7.

5. Sardana A, Kalra S, Khanna D, Balakumar P. Nephroprotective effect of catechin on gentamicin-induced experimental nephrotoxicity. Clin Exp Nephrol. 2015;19(2):178-84.

6. Dungca NTP. Protective effect of the methanolic leaf extract of Eclipta alba ( L .) Hassk. (Asteraceae) against gentamicin-induced nephrotoxicity in Sprague Dawley rats. J Ethnopharmacol. 2016;184:18-21.

7. Thaman RR, Thomson LAJ, DeMeo R, Areki F, Elevitch CR. Species profile for pacific island agroforestry. Agroforestree database ICRAF. 2006:1-17.

8. Hendriati L, Kresnamurti A, Widodo T, Ivani EN, Anrika MY. Hypoglycemic effect and hypersensitivity test of transdermal patch dosage form containing Angsana ( Pterocarpus indicus Willd .) Extract. Jurnal Farmasi Sains dan Terapan. 2015;2(2):15-9.

9. Takeuchi S, Kono HY, Mizutani T, Maruyama K, Nakayama R, Hiraoka A, et al. A Bioactive polyphenolic constituent in the bark of Pterocarpus indicus Willd. I. isolation and characterization. Agric Biol Chem. 1986;50(3):569-73.

10. Tanabe K, Tamura Y, Lanaspa MA, Miyazaki M, Suzuki N, Sato W, et al. Epicatechin limits renal injury by mitochondrial protection in cisplatin nephropathy. Am J Physiol Renal Physiol. 2012;303(9):1264-74.

11. Ministry of Health. Indonesian Materia Medica. 6th ed. Jakarta: Ministry of Republic Indonesia; 1995.

12. Human Gesellschaft fur Biochemica und Diagnostic, Urea liquid color. Enzymatic Colorimetric Test for Urea. 2003. Available from http://www.standard. com.tw/standard/t_standard/system_manager/tw/products/uploadFile/57/Surlqc(UREA).pdf

13. Human Gesellschaft fur Biochemica und Diagnostic., Creatinine liquicolor: Jaffe Reaction. 2003. Available from : http://www.standard.com.tw/standard/t_standard/system_manager/tw/products/uploadFile/65/Su-crea1(CREATININE).pdf

14. Mishra S, Pani SR, Sahoo S. Anti-nephrotoxic activity of some medicinal plants from tribal rich pockets of Odisha. Pharmacognosy Res. 2014;6(3):210-7.

15. Rahmat AA, Dar FA, Choudhary IM. Protection of $\mathrm{CCl}_{4}$-induced liver and kidney damage by phenolic compounds in leaf extracts of Cnestis ferruginea (de candolle). Pharmacognosy Res. 2014;6(1):19-28.

16. Varatharajan R, Jun LH, Kai TZ, Jian LW, Anburaj J, Vijayan V. Morphological and morphometric study of edaravone in gentamicin-induced nephrotoxicity in sprague dawley rats. J Young Pharm. 2017;9(1):31-5.

17. Hegazy AMS, Mosaed MM, Elshafey SH, Bayomy NA. 6-Gingerol ameliorates gentamicin-induced renal cortex oxidative stress and apoptosis in adult male albino rats. Tissue Cell. 2016;48(3):208-16.

18. Almulaiky YQ, Alshawafi WM, Al-Talhi HA, Zeyadi M, Anwar F, Al-abbasi FA, et al. Evaluation of the antioxidant potential and antioxidant enzymes of some Yemeni grape cultivars. Free Radicals and Antioxidant. 2017;7(1):74-9.

19. Nijveldt RJ, Nood E, Hoorn DE, Boelens PG, Norren K. Leeuwen P. Flavonoids: a review of probable mechanisms of action and potential applications. Am J Clin Nutr. $2001 ; 74(4): 418-25$.

20. Research Animal Resource; University of Minnesota. Reference values for laboratory animals: normal chemistry values. University of Minnesota; 2009. Available from:http://www.ahc.umn.edu/rar/refvalues.html.

Article History: Submission Date: 20-12-16; Revision Date: 07-01-17; Accepted Date:13-01-17.

Cite this article: Saputri FC, Anjani FD, Mun'im A. Nephroprotective Effect of Pterocarpus indicus Willd. Leaves: Observation From Plasma Urea and Creatinine Levels Against Gentamicin-Induced Nephrotoxicity in Sprague-Dawley Rats. JYoung Pharm. 2017;9(1)Suppl:s43-s5. 